\title{
SANEAMENTO BÁSICO versUs DOENÇAS DE VEICULAÇÃO HÍDRICA NO MUNICÍPIO DE PELOTAS/RS
}

\author{
M.F. AGUIAR ${ }^{1}$, S.T. CECCONELLO ${ }^{2}$, L.N. CENTENO ${ }^{3}$ \\ Instituto Federal de Educação, Ciência e Tecnologia Sul-Riograndense ${ }^{1,2}$, Universidade Federal de Pelotas ${ }^{3}$ \\ satolentino@pelotas.ifsul.edu.br ${ }^{2}$
}

Artigo submetido em 15/11/2015 e aceito em 24/06/2019

DOI: $10.15628 /$ holos. 2019.7940

\section{RESUMO}

Apesar do avanço do Brasil nos últimos anos, ainda há sérios problemas com a deficiência do serviço de saneamento básico no país, principalmente em relação à coleta e tratamento de esgoto. Diante isto, este estudo teve como objetivo realizar um levantamento das principais doenças de veiculação hídrica relacionadas à falta de saneamento básico encontradas no município de Pelotas/RS entre os anos de 2007 e 2017. Os dados para o presente trabalho foram obtidos junto ao Departamento de Vigilância Epidemiológica de Pelotas e o site do DATASUS para o período de 2007 a 2015, para a diarréia e dengue, e 2007 a 2017 para hepatite A e leptospirose. A análise estatística foi realizada através dos valores de medidas de posição central, medidas de dispersão e das medidas da forma de dispersão. Os valores de Coeficiente de Variação foram analisados conforme proposto por Wilding; Drees em 1983. Onde foi possível observar que a diarréia foi a doença que mais ocorreu em Pelotas durante os anos de 2007 a 2015, seguido da hepatite A, leptospirose e dengue. Conclui-se com este trabalho, a necessidade de um maior investimento por parte dos órgãos responsáveis, em propiciar um saneamento ambiental de boa qualidade à população, pois é uma das principais maneiras de evitar contrair as doenças de veiculação hídrica que foram apresentadas neste estudo. Além disso, a população em geral deve estar atenta e colaborar com a infraestrutura e instalações operacionais de abastecimento de água, esgotamento sanitário, limpeza urbana, drenagem urbana, manejos de resíduos sólidos e de águas pluviais, pois as precipitações podem interferir negativamente nas ocorrências das doenças de veiculação hídrica no município de Pelotas, decorrentes da falta de saneamento.

PALAVRAS-CHAVE: Doenças de veiculação hídrica, DataSus, Ministério da Saúde, Esgoto.

\section{BASIC SANITATION versUs WATER VEHICULATION DISEASES IN THE MUNICIPALITY OF PELOTAS / RS ABSTRACT}

Despite progress in recent years, there are still problems with reducing the pace of life in the country, especially in relation to sewage collection and treatment. Given this, this study had an attempt to obtain a description of the main waterborne diseases related to the lack of information about the deficiencies in the municipality of Pelotas / RS between the years of 2007 and 2017. Data for the present study were obtained from the Department of Epidemiological Surveillance of Pelotas and the DATASUS website for the period from 2007 to 2015, for diarrhea and dengue, and from 2007 to 2017 for hepatitis A and leptospirosis. Statistical analysis was performed using the values of central position measurements, dispersion measurements and dispersion shape measurements. The coefficient of variation values were analyzed as proposed by
Wilding; Drees in 1983. Where it was possible to observe that diarrhea was the most frequent disease in Pelotas during the years 2007 to 2015, followed by hepatitis A, leptospirosis and dengue. It is concluded with this work, the need for greater investment by the responsible agencies, in order to provide a good quality environmental sanitation to the population, as it is one of the main ways to avoid contracting the waterborne diseases that were presented in this study. In addition, the population in general must be attentive and cooperate with the infrastructure and operational facilities for water supply, sewage, urban cleaning, urban drainage, solid waste and stormwater management, as precipitation can negatively interfere in the occurrences of waterborne diseases in the municipality of Pelotas, due to lack of sanitation.

KEYWORDS: Water-borne diseases, DataSus, Ministry of Health, Sewage .

HOLOS, ANO 35, v.3, e7940, 2019 


\section{INTRODUÇÃO}

Com o surgimento do sistema capitalista e com a Revolução Industrial os meios de produção se alteraram, inferindo diretamente no uso dos recursos naturais, gerando acentuados impactos ambientais, como a escassez de recursos hídricos e a grande produção de resíduos sólidos (NOMURA et al., 2017). O descarte inadequado dos resíduos sólidos, o acúmulo das águas pluviais e a falta de coleta e tratamento do esgoto sanitário são os grandes responsáveis diretos e indiretos pela veiculação de doenças hídricas (SANTOS et al., 2018; FERREIRA et al., 2016).

Apesar da ampla abrangência na caracterização do termo "saneamento básico" a Lei Federal no. 11.445, de 05 de janeiro de 2007 que estabelece as diretrizes nacionais para o saneamento básico, o define como um conjunto de serviços de: infraestrutura e instalações operacionais de abastecimento de água; esgotamento sanitário; limpeza urbana; drenagem urbana, manejos de resíduos sólidos e de águas pluviais e o controle de vetores (BRASIL, 2007).

Todavia em território nacional esse serviço atende basicamente o abastecimento de água, a coleta e disposição de resíduos sólidos e coleta de esgoto, não satisfazendo adequadamente os serviços de tratamento e disposição final de esgotos, drenagem urbana e o controle de vetores (OLIVEIRA et al., 2015).

Contudo o país possui uma rede abrangente de abastecimento de água, embora esta ainda não esteja acessível a toda população brasileira (GARCIA; FERREIRA, 2017). Apesar do avanço do Brasil nos últimos anos, ainda há sérios problemas com a deficiência do serviço de saneamento básico (OLIVEIRA et al., 2015), principalmente em relação à coleta e tratamento de esgoto (GARCIA; FERREIRA, 2017).

De acordo com o Sistema Nacional de Informação do Saneamento - SNIS (2016), o Rio Grande do Sul, apresenta $86,40 \%$ dos municípios atendidos com rede de abastecimento de água, 30,22\% dos municípios com coleta de esgotos e destes apenas $25,22 \%$ tratam seus esgotos.

Situação similar à do estado do Rio Grande do Sul, o município de Pelotas apresenta 96,76\% da população atendida com rede de abastecimento de água e 59,03\% da população é atendida com rede coletora de esgoto, porém apenas $19,20 \%$ do esgoto é tratado no município (SNIS, 2016).

Deste modo, a deficiência e ou a ineficiência desses serviços causa impactos negativos na educação, trabalho, economia, biodiversidade, entre outros (GARCIA; FERREIRA, 2017; OLIVEIRA et al., 2015). É pertinente destacar que, uma pesquisa da Fundação Getúlio Vargas em 2015 revelou que as crianças que viviam e estudavam em um ambiente sem condição sanitária apropriada, tiveram aproveitamento $18 \%$ menor e apresentavam índices de reprovação $46 \%$ maior, do que aquelas que viviam e estudavam em ambientes com uma condição sanitária adequada (OLIVEIRA et al., 2015).

HOLOS, ANO 35, v.3, e7940, 2019 
Esse fato comprova que a falta de saneamento básico adequado causa um impacto negativo no aproveitamento escolar das crianças, comprometendo o futuro da pirâmide social de um país, pois os indivíduos deixam de aprender e se desenvolver intelectualmente na fase mais importante da vida, ou seja, quando ainda são crianças (OLIVEIRA et al., 2015).

Sendo assim, a falta de saneamento básico interfere negativamente na qualidade de vida do cidadão e eleva o nível de susceptibilidade da população às doenças de veiculação hídrica (FERREIRA et al., 2016). Essas doenças infecto-parasitárias foram classificadas por Cairncross e Feachem (1993), como "Doenças Relacionadas ao Saneamento Ambiental Inadequado" (DRSAI), que podem ser evitadas, bastando apenas que possibilite condições que garantam a salubridade ambiental (SIQUEIRA et al., 2017).

As DRSAI são classificadas em: doenças de transmissão feco-oral (bacterianas e não bacterianas); helmintos transmitidos pelo solo e água; tênias (solitárias) e doenças transmitidas por insetos vetores relacionados com as fezes (OLIVEIRA et al., 2015).

Deste modo, diversas enfermidades estão relacionadas com a falta de saneamento básico, ou seja, doenças que são transmitidas através da ingestão de água contaminada; contato com resíduos ou solos contaminados; contato com vetores como os parasitas e mosquitos que se proliferam em locais de esgoto a céu aberto; disposição final inadequada de resíduos sólidos; rios poluídos, entre outros (CAMARGO et al., 2017).

Portanto, os indivíduos que não tem as condições mínimas de qualidade de saneamento estão diretamente expostas as doenças supracitadas. Entre as medidas mínimas para garantir a saúde da população, podemos citar as obras e serviços de abastecimento de água; coleta de esgotos; controle de vetores e disposição final adequada dos resíduos sólidos; além de acesso às informações sobre medidas de prevenção; cuidados e controle dos focos dos vetores (FARIAS et al., 2016).

É pertinente destacar que para garantir a boa qualidade dos serviços de saneamento básico, várias leis foram criadas, entre elas: a Lei no. 10.257/2001, denominada Estatuto da Cidade (IBGE, 2010); a Lei no. 11.445/2007 - Lei de Saneamento Básico (BRASIL, 2007); Lei Federal no 12.305/10 Política Nacional de Resíduos Sólidos (BRASIL, 2010). E em julho de 2011 a Organização Mundial da Saúde (OMS) lançou uma edição normativa sobre a qualidade da água para consumo humano (NOMURA et al., 2017).

Além disso, a higiene, como o simples ato de lavar as mãos (reduzindo a incidência de diarréia e de infecção hospitalar); lavar as roupas; banhar-se; conservar limpo o ambiente em que se vive (evitar dispor resíduos sólidos em locais inapropriados), evitando a proliferação de ratos e insetos; bem como cuidar da lavagem dos alimentos utilizados nas refeições, são as formas mais eficazes para evitar grande parte das moléstias supracitadas (OLIVEIRA et al., 2015).

HOLOS, ANO 35, v.3, e 7940, 2019 
Sendo assim, o levantamento e análise das principais doenças de veiculação hídrica em um município, pode auxiliar na redução dos impactos gerados em uma comunidade, pois permite inferir sobre as áreas de maior vulnerabilidade, ou seja, das áreas que mais sofrem com os problemas decorrentes da falta de saneamento básico e que necessitam de medidas corretivas. Dentre as ferramentas utilizadas para auxiliar na identificação das áreas de maior vulnerabilidade, podemos citar a estatística.

A estatística pode servir de meio para verificar se ocorre influência da heterogeneidade temporal sobre a representatividade dos valores médios (CHAVES et al., 2009) e assim obter uma descrição dos dados analisados. As medidas de posição permitem a verificação de um possível ajuste dos dados na distribuição normal, enquanto que o coeficiente de variação apresenta a magnitude de variabilidade dos atributos analisados (MOURÃO, 2014). Em suma é possível analisar a intensidade e ocorrência de focos de doenças de veiculação hídrica através do uso da estatística.

Diante do exposto, este trabalho objetivou realizar um levantamento das principais doenças de veiculação hídrica relacionadas à falta de saneamento básico encontradas no município de Pelotas/RS entre os anos de 2007 e 2017.

\section{METODOLOGIA}

\subsection{Caracterização da área}

O município de Pelotas está localizado no estado do Rio Grande do Sul, no extremo sul do Brasil, na Latitude: 31 46' 19" S e Longitude: 52 20' 33" W, situado às margens do Canal São Gonçalo que liga as Lagoas dos Patos e Lagoa Mirim. Ocupa uma área de 1.610,084 km², sendo que cerca de 92,00\% da população total reside na zona urbana. Apresenta uma população estimada para 2017 de 344.385 pessoas (IBGE, 2017).

O Serviço Autônomo de Saneamento de Pelotas (SANEP) é o responsável por captar, tratar e distribuir a água potável, além de coletar e tratar o esgoto do município. A coleta e a destinação dos resíduos sólidos também são de responsabilidade do SANEP (serviços terceirizados). Na Figura 1 está representada a localização do município de Pelotas/RS e a área urbana do município, região foco deste estudo. 


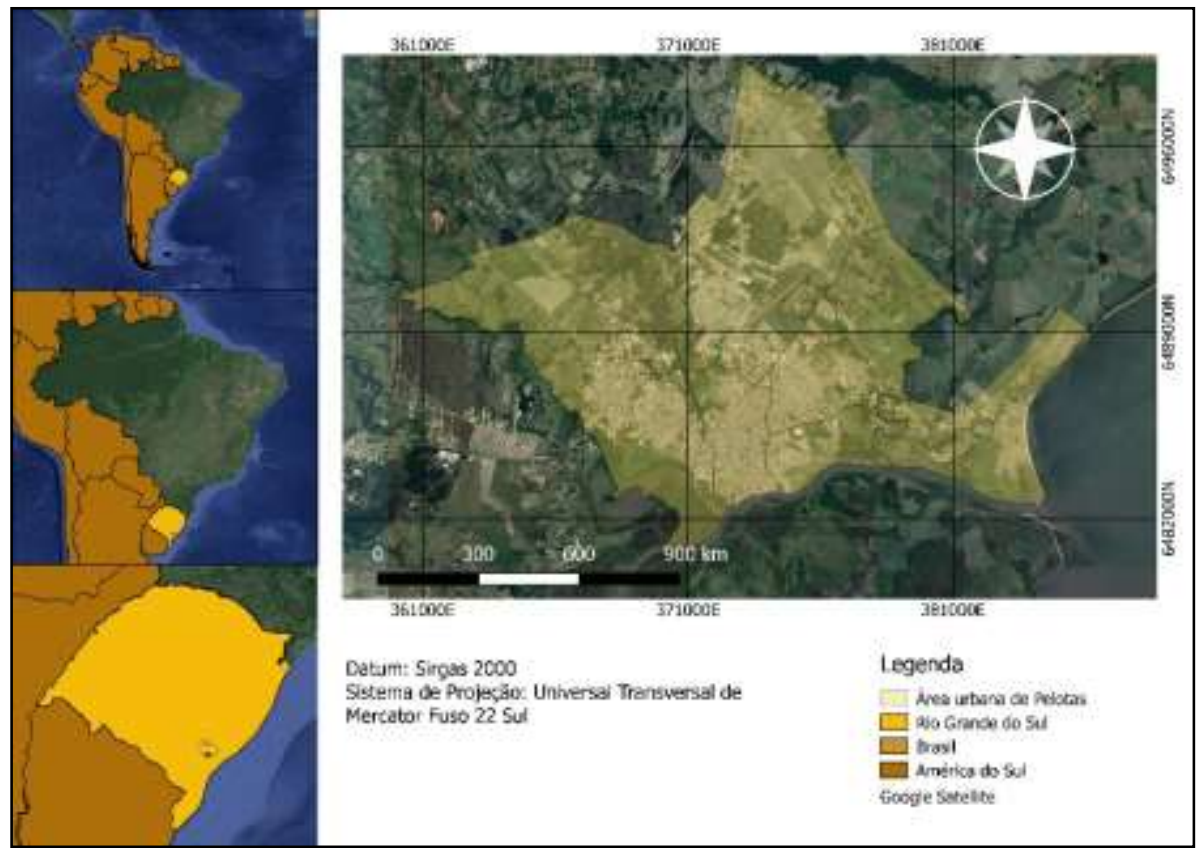

Figura 1: Mapa de localização do município de Pelotas/RS.

\subsection{Obtenção dos dados}

Os dados para o presente estudo foram obtidos junto ao Departamento de Vigilância Epidemiológica do município de Pelotas e pelo site do Departamento de Informática do Sistema Único de Saúde - DATASUS para o período de 2007 a 2015, para as seguintes doenças: diarréia e dengue e referente ao período de 2007 a 2017 para a leptospirose e hepatite A. Os dados obtidos referem-se apenas a zona urbana do município, pois não foram encontrados dados referentes à zona rural nas fontes supracitadas.

Foram obtidos os dados de precipitação para o município de Pelotas/RS através da estação pluviométrica da Agência Nacional das Águas - ANA Ponte Cordeiro de Farias para a série histórica estudada. Os dados foram obtidos diretamente do site da ANA (2018) no formato .mdb e estes foram abertos no software HidroWeb. No HidroWeb foram selecionadas as precipitações médias anuais para os anos de 2007 a 2017. Posteriormente gerou-se o histograma da precipitação média anual em uma planilha eletrônica.

\subsection{Análise Estatística}


A análise estatística dos dados foi realizada através dos valores de medidas de posição central média, mediana, valores máximos e mínimos; medidas de dispersão como o coeficiente de variação (C.V(\%)) e das medidas da forma de dispersão assimetria (ASS) e curtose (CURT).

Os valores de C.V (\%) foram analisados conforme proposto por Wilding; Drees (1983): CV $\leq 15 \%$ - baixa dispersão dos dados; $15 \%<C V \leq 35 \%$ - moderada dispersão; CV > 35\% - alta dispersão. A análise exploratória foi realizada ainda através de gráficos em barras a fim de realizar uma análise histórica das doenças de veiculação hídrica analisadas. Todos os procedimentos estatísticos foram realizados no EXCEL ${ }^{\circledR}$.

\section{RESULTADOS E DISCUSSÃO}

Após a obtenção dos dados de precipitação para Pelotas/RS junto a ANA, obteve-se o histograma da precipitação anual média, conforme a Figura 2.

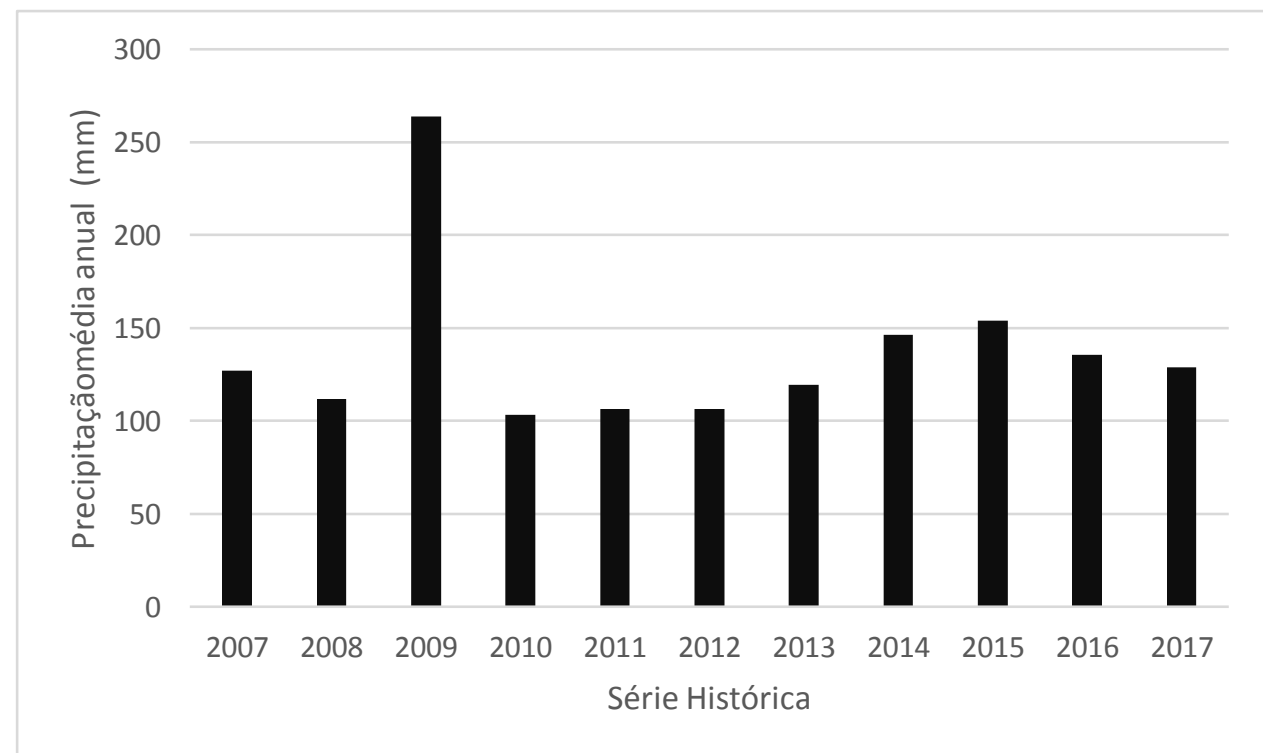

Figura 2: Precipitação média anual para o município de Pelotas/RS 2007-2017.

Observa-se que nos anos de 2009 e 2015 foram as maiores precipitações entre os anos estudados. Neste período há registros de inundação no município conforme Hansmann (2013) e Portal G1 notícias (2015).

Dentre as principais doenças de veiculação hídrica, ocorridas no município de Pelotas a Tabela 1 apresenta a estatística descritiva dos dados obtidos para a série estudada.

HOLOS, ANO 35, v.3, e7940, 2019 
Tabela 1: Estatística descritiva das principais doenças de veiculação hídrica ocorridas na zona urbana do município de Pelotas/RS entre os anos de 2007 e 2017.

\begin{tabular}{ccccc}
\hline & Diarréia & Dengue & Hepatite A & Leptospirose \\
\hline Média & 445,22 & 1,89 & 135,73 & 11,45 \\
Mediana & 450,00 & 1,00 & 106,00 & 10,00 \\
Desvio padrão & 113,33 & 1,54 & 93,99 & 6,47 \\
Coeficiente de variação (\%) & 25,46 & 81,35 & 69,25 & 56,49 \\
Variância da amostra & 12844,69 & 2,36 & 8834,02 & 41,87 \\
Mínimo & 297,00 & 0,00 & 27,00 & 5,00 \\
Máximo & 657,00 & 5,00 & 339,00 & 28,00 \\
No de casos & 4007 & 15 & 1493 & 126 \\
\hline
\end{tabular}

Ao analisar a Tabela 1 observa-se que a diarréia foi a doença que mais ocorreu em Pelotas, seguindo esta, a hepatite $A$, leptospirose e dengue. O coeficiente de variação de $81,35 \%$ para dengue demonstra que esta doença apresentou alta variabilidade durante os anos estudados. Para a hepatite A e leptospirose também se obteve um coeficiente de variação acima de 35,00\%, o que indica que estas também tiveram grande variabilidade ao longo dos anos. Já a diarréia apresentou variabilidade média para a série estudada (WILDING; DREES, 1983). O que significa dizer que a ocorrência das três primeiras doenças foram as mais heterogêneas ao longo da série temporal estudada enquanto a diarréia apresentou dados mais homogêneos. Provavelmente os casos de diarréia possam ser explicados pela ingestão ou contato com alimento ou água contaminada.

Observa-se que o mínimo de ocorrência de diarreia no município por ano foi de 297 casos e o máximo de 657, em oposição tiveram anos que a dengue não apresentou ocorrência, sendo que a mesma apresentou o máximo de 5 ocorrências anual em toda a série histórica. A dengue é causada pelo vírus que infecta o mosquito Aedes aegypti e este transmite para os seres humanos através da picada. O mosquito se prolifera rapidamente, deste modo é muito importante que se mantenha o ambiente isento de resíduos sólidos e água parada.

Observa-se na Figura 3 que as maiores incidências de diarréia ocorreram nos anos de 2008, seguidos de 2010, 2012 e 2014. 


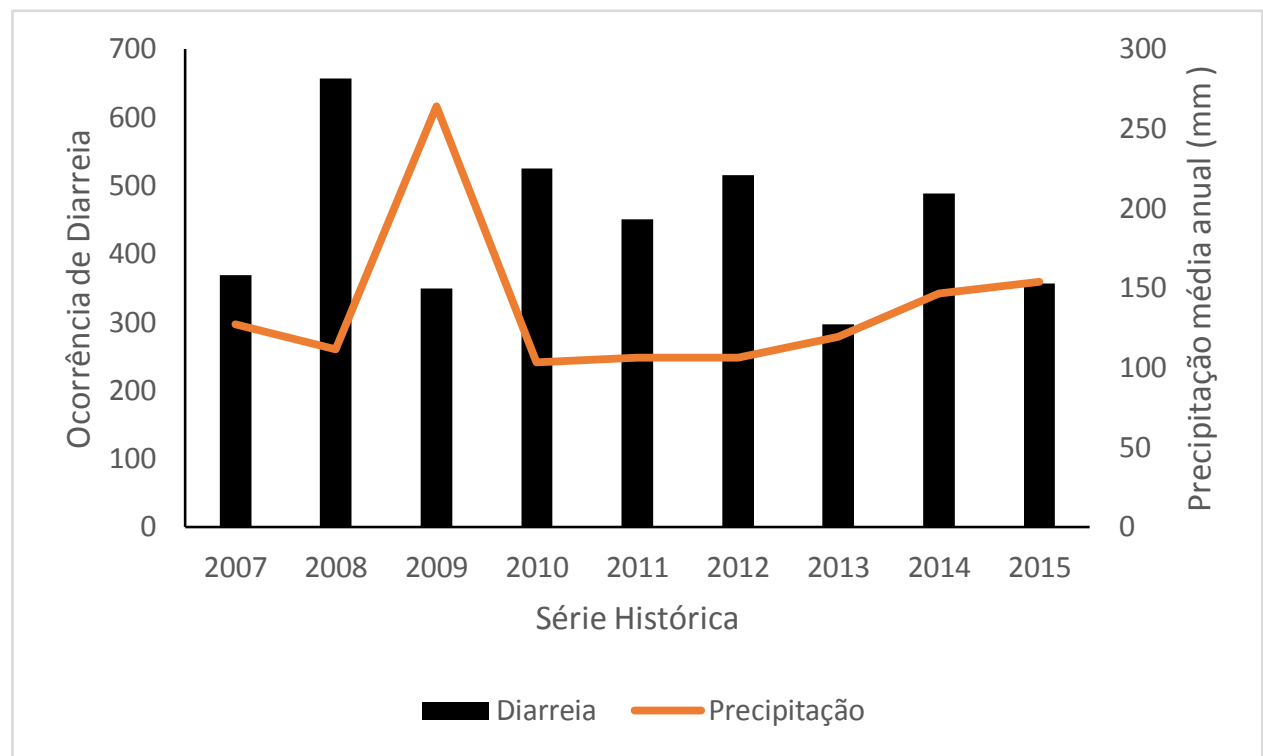

Figura 3: Notificação de diarréia, na zona urbana do município de Pelotas, ocorrido no período de 2007 a 2015.

A diarréia se caracteriza principalmente pelo aumento do número de evacuações e pela falta de consistência das fezes, que se tornam aguadas levando o indivíduo à desidratação. As causas podem ser: toxinas bacterianas como a do Estafilococus; falta de higiene; infecções causadas por bactérias como a Salmonella e a Shighella; infecções virais; disfunção da motilidade do tubo digestivo; parasitas intestinais transportados por água ou comida contaminada causando a amebíase e a giardíase; efeitos colaterais de algumas drogas, por exemplo, antibióticos, altas doses de vitamina $\mathrm{C}$ e alguns medicamentos para o coração e câncer; abuso de laxantes e intolerância à lactose (açúcar do leite) e ao sorbitol (adoçante obtido a partir da glicose) (BRUNA, 2018). De acordo com a Figura 3, observa-se que as maiores ocorrências de diarréia ocorreram em períodos em que a precipitação foi menor, corroborando para uma relação negativa entre estas variáveis, ou seja, a diarréia não tem relação direta com a precipitação e sim pode ter com ingestão de alimento ou água contaminada.

Uma das formas para evitar a contaminação é lavar bem as mãos várias vezes ao dia e principalmente antes das refeições e ferver ou filtrar a água não tratada que será utilizada tanto para beber, como na preparação da alimentação que será consumida e fazer gelo com água tratada ou fervida (BRUNA, 2018).

Por conseguinte, com relação à leptospirose (Figura 4) é possível observar que no ano de 2010 ocorreram mais de 25 casos da doença na zona urbana do município, sendo que nos anos de 2012 e 2017 foram os de menores incidências da doença. 


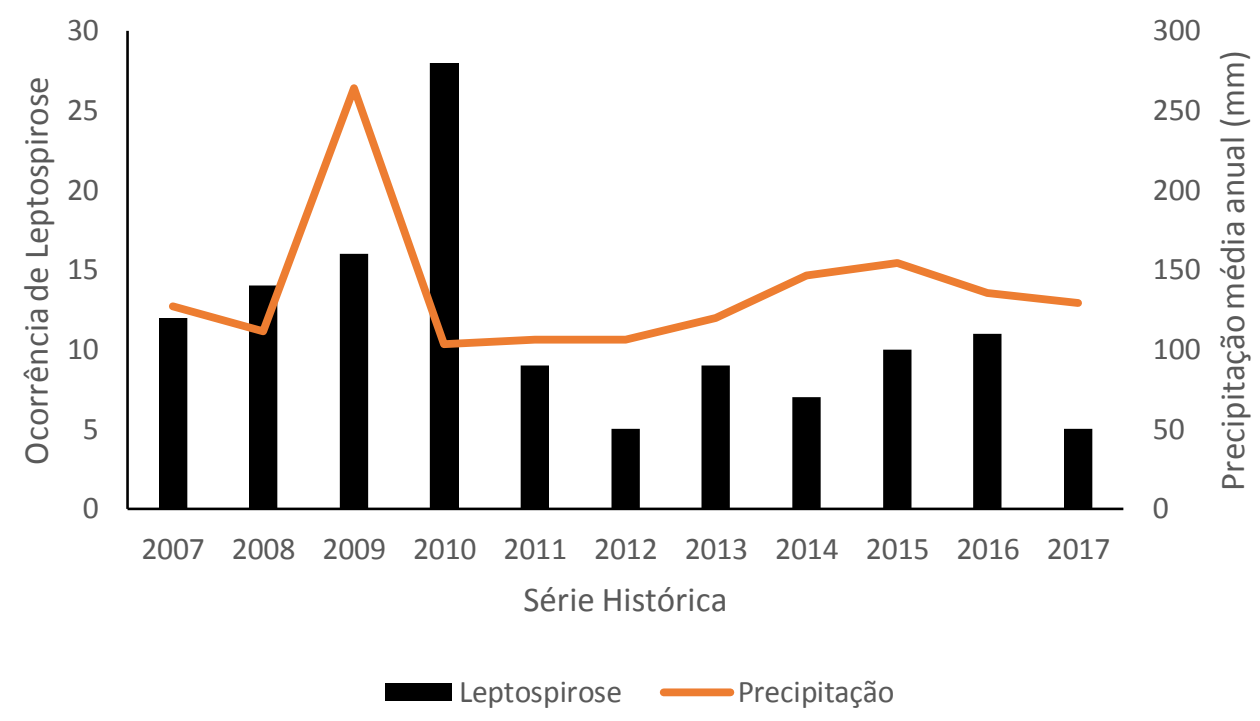

Figura 4: Notificação de leptospirose, na zona urbana do município de Pelotas, ocorrido entre 2007 a 2017.

A leptospirose é uma enfermidade mundial que infecta tanto os animais quanto os humanos, é causada pela bactéria patogênica Leptospira, que se insere no corpo do hospedeiro através de membranas mucosas e conjuntivas, lesões e abrasões e também na pele que fica muito tempo em contato com a água ou solo contaminado (GUEDES, 2017).

A falta de saneamento (infraestrutura e instalações operacionais de abastecimento de água; esgotamento sanitário; limpeza urbana; drenagem urbana; manejos de resíduos sólidos e de águas pluviais) além da água contaminada pela urina de animais infectados é um meio de dispersão da Leptospira, pois essa é carreada pelas enchentes e alagamentos e se mantém viva por um longo tempo (GUEDES, 2017). Pelo gráfico da precipitação pluviométrica verifica-se que o maior índice de chuvas ocorreu no ano de 2009 e já no ano seguinte, ou seja, em 2010 foi registrado em Pelotas o maior número de casos de leptospirose. A precipitação pluviométrica e a leptospirose possuem relação direta entre elas, pois o vírus da Leptospira se propaga através das enchentes e alagamentos, que em contato com o ser humano, acaba por infectá-lo. Porém, neste estudo os altos índices de casos registrados da doença podem estar relacionados com o esgoto à céu aberto em valetas e ou acúmulo de resíduos sólidos em local inadequado.

O crescimento desordenado das cidades, a falta de saneamento ambiental e a falta de planejamento urbano, tornam a população mais susceptível aos desastres naturais, desta forma é imprescindível que sejam adotadas medidas mitigadoras com o propósito de evitar a ocorrência e prevenir surtos dessa doença (SOARES et al.,2014). 
Com relação à hepatite A as maiores ocorrências ocorreram no ano de 2009 em contraponto, o menor número de incidentes foi em 2013 (Figura 5), sendo este inferior a 50 casos, contudo a hepatite A é uma doença de distribuição mundial, considerada como uma das importantes doenças virais agudas em todo o mundo (NUNES et al., 2016), causando grande impacto na saúde pública, podendo resultar em óbitos e internações (PINHEIRO et al., 2015).

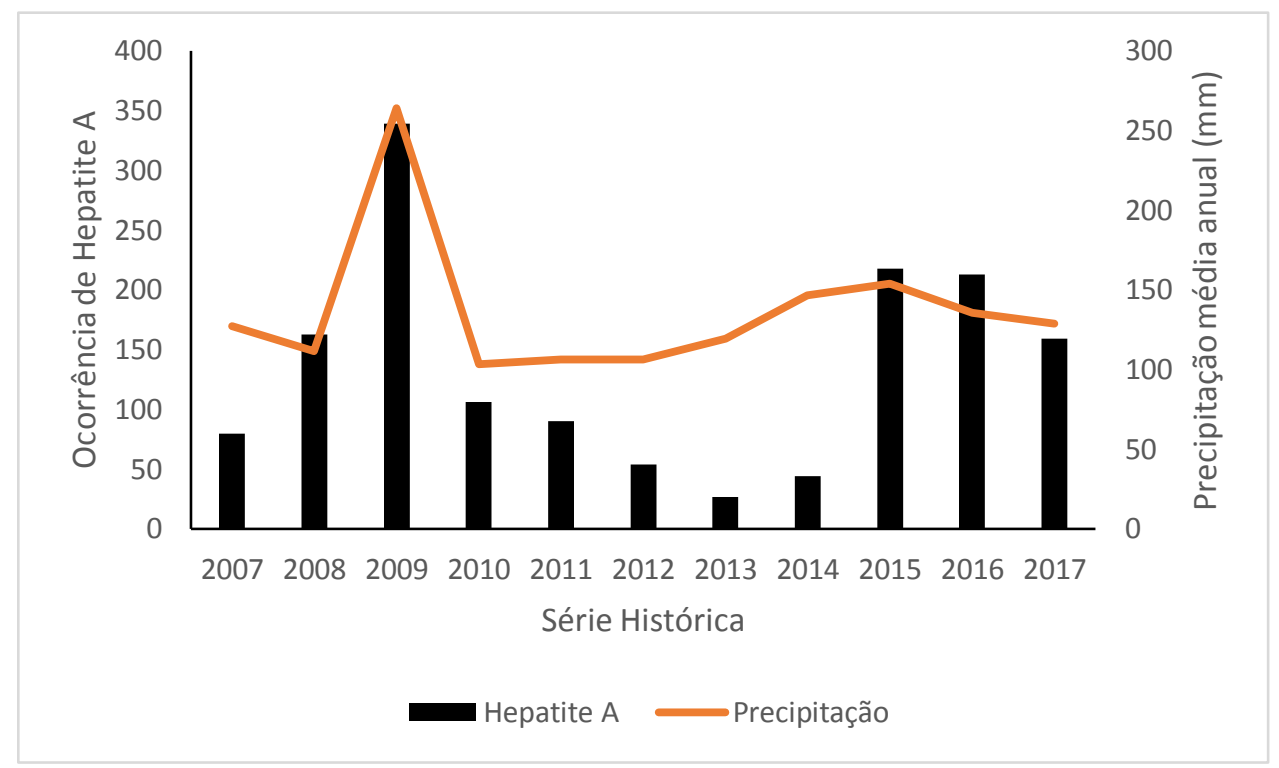

Figura 5: Notificação de hepatite, na zona urbana de Pelotas, ocorrido entre 2007 e 2017.

Observa-se que em 2009 as ocorrências de hepatite A tiveram uma forte relação com a precipitação, provavelmente devido aos alagamentos que ocorreram na cidade neste período.

A dengue (Figura 6) apresentou maiores ocorrências no ano de 2010 e nenhum caso em 2007. A dengue de acordo com Farias et al.; (2016), é uma doença viral transmitida pelo mosquito Aedes aegypti, foi identificada no Brasil, pela primeira vez em 1986. E estima-se que anualmente ocorram 50 milhões de infecções por dengue no mundo (BRASIL, 2018). 


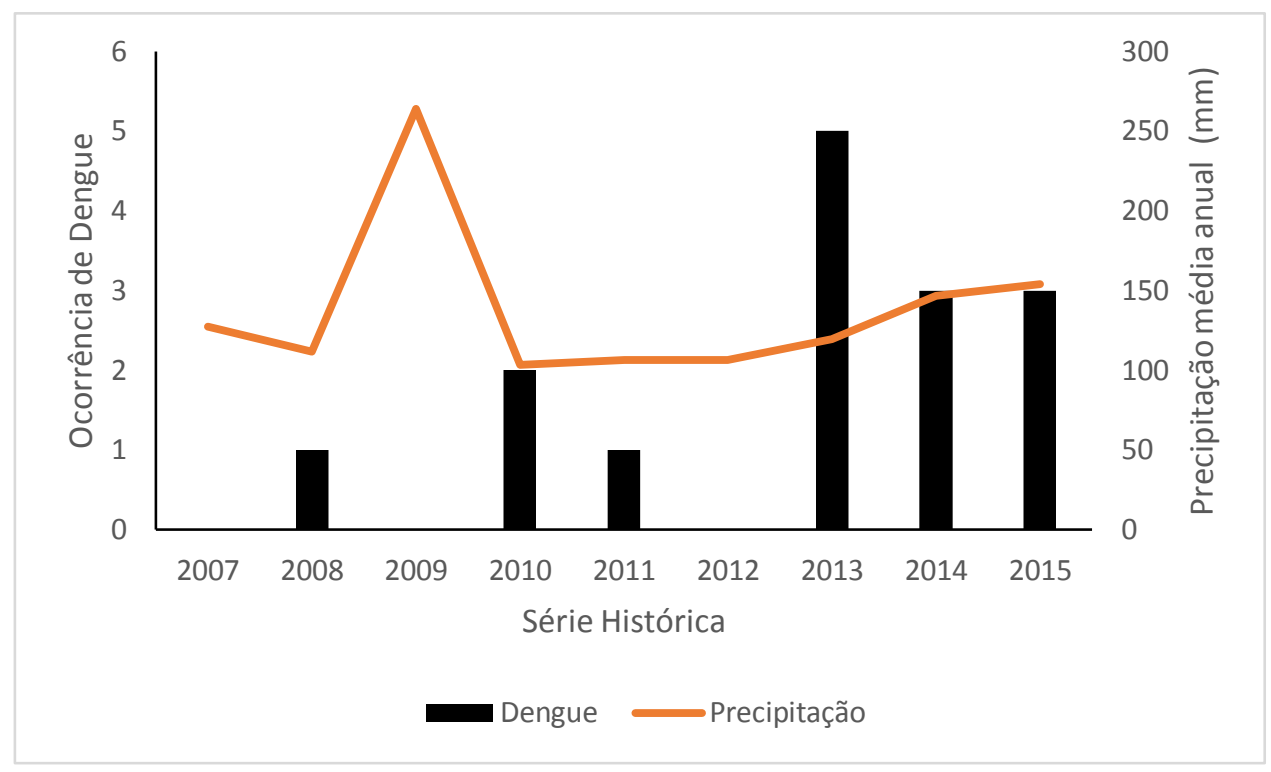

Figura 6: Notificação de dengue, na zona urbana de Pelotas, ocorrido no período de 2007 a 2015

Observa-se na Figura 6 que as ocorrências de dengue em Pelotas apresentam relação negativa com a precipitação, porém não foi este o único fator, sendo que um dos fatores que contribuem com a ocorrência da doença é a disposição final inadequada de resíduos sólidos, bem como água armazenada inadequadamente.

A população tem grande responsabilidade nesse controle, tendo o cuidado de manter o domicílio limpo, eliminando os possíveis criadouros (BRASIL, 2018), (vasilhames temporários, barris, pneus usados, latas, garrafas, vasos de plantas, calhas de telhado dentre outros). Esses cuidados devem ser adotados permanentemente e não apenas quando as temperaturas estiverem mais altas (FARIAS et al., 2016).

Cabe destacar que a saúde é um direito garantido pelo estado, para tanto, medidas devem ser tomadas para reduzir as doenças, promover, proteger e recuperar a saúde da população. Todavia a população tem grande responsabilidade nesse controle, tendo o cuidado de manter o domicílio limpo, eliminando os possíveis criadouros (BRASIL, 2018), ingerindo água clorada ou fervida; lavando as mãos antes das refeições e depois de usar o sanitário (BRUNA, 2018) além de ter a consciência de descartar seus resíduos em locais apropriados.

Ademais, efetivas políticas públicas devem ser implementadas com o objetivo de desenvolver e melhorar os sistemas de abastecimento de água e esgotamento sanitário (PINHEIRO et al., 2015), como por exemplo: disponibilização de água potável em qualidade e quantidade suficiente para a população; utilização das fossas sépticas e apresentar coleta e tratamento dos esgotos sanitários; dentre outros, a destinação correta dos resíduos sólidos (NUNES et al., 2016).

HOLOS, ANO 35, v.3, e7940, 2019 
Além dessas medidas, a população precisa ser esclarecida sobre a transmissão, o tratamento e a prevenção das doenças de veiculação hídrica, para assim valorizarem, as medidas de saneamento acima mencionadas (NUNES et al., 2016), com o objetivo de reduzir o número de enfermos e óbitos, causados por estes tipos de enfermidades (PINHEIRO et al., 2015; BARACHO et al., 2017; SOARES et al., 2014).

\section{CONCLUSÃO}

Conclui-se com este trabalho, a necessidade de um maior investimento por parte dos órgãos responsáveis, em propiciar um saneamento ambiental de boa qualidade à população, pois é uma das principais maneiras de evitar contrair as doenças de veiculação hídrica que foram apresentadas neste estudo. Além disso, a população em geral deve estar atenta e colaborar com a infraestrutura e instalações operacionais de abastecimento de água, esgotamento sanitário, limpeza urbana, drenagem urbana, manejos de resíduos sólidos e de águas pluviais, pois as precipitações podem interferir negativamente nas ocorrências das doenças de veiculação hídrica no município de Pelotas, decorrentes da falta de saneamento.

\section{REFERÊNCIAS BIBLIOGRÁFICAS}

BARACHO, J M, LIMA, N de B \& COSTA, A P R da C. (2017) Incidência De Casos De Leptospirose Humana Em Pernambuco: Uma Análise Dos Dados Epidemiológicos De 2015. Ciências Biológicas e de Saúde Unit. FACIPE. v. 3. n. 2. p. 19-32. Novembro 2017. periodicos.set.edu.br.

BRASIL. Lei no. 11.445, de 05 de janeiro de 2007. Estabelece diretrizes nacionais para o saneamento básico; altera as Leis nos 6.766, de 19 de dezembro de 1979, 8.036, de 11 de maio de 1990, 8.666, de 21 de junho de 1993, 8.987, de 13 de fevereiro de 1995; revoga a Lei no 6.528, de 11 de maio de 1978; e dá outras providências.

BRASIL. Ministério da Saúde. (2018) Prevenção e combate dengue, chikungunya e zika. Disponível em: <http://combateaedes.saude.gov.br/pt/tira-duvidas\#dengue>. Acesso em: 16 ago. 2018

BRUNA, M. H. V.. Diarreia. 2018. Disponível em: <https://drauziovarella.uol.com.br/doencas-esintomas/diarreia/>. Acesso em: 14 ago. 2018.

CAMARGO, D M de, SOUZA, N M, PACHECO, T C K F, ALCÂNTARA, G C \& DOTA, E M. (2017) Modelagem Geoespacial Para Identificação De Áreas Vulneráveis Ao Contágio Por Doenças Relacionadas À Falta De Saneamento: O Caso Da Região Metropolitana De Campinas - Revista Brasileira de Cartografia (2017), No 69/3: 561-573. ISSN: 1808-0936. 
CHAVES, L. H. G., \& FARIAS, C. H. A. (2009) Variabilidade Espacial De Cobre E Manganês Em Argissolo Sob Cultivo De Cana-De-Açúcar. Revista Ciência Agronômica, v.40, p. 211-218, 2009.

FARIAS, L M, SILVA, R. N, \& MAGGI, L. E. M. (2016) Análise De Focos Do Aedes Aegypti Em Três Bairros De Rio Branco - Acre, 2016 - Journal of Amazon Health Science. Vol.2, n.1. <http:// revistas.ufac.br/revista/index.php/ahs/índex>

FERREIRA, P.S. F. MOTTA, P.C, SOUZA, T.C, SILVA, T.P, OLIVEIRA, J.F, \& SANTOS, A.S.P. (2016) Avaliação preliminar dos efeitos da ineficiência dos serviços de saneamento na saúde pública brasileira. Revista Internacional de Ciências, [s.I.], v. 6, n. 2, p.214-229, 22 dez. 2016. Universidade de Estado do Rio de Janeiro. http://dx.doi.org/10.12957/ric.2016.24809.

G1 PORTAL DE NOTÍCIAS (Rio Grande do Sul). Globo Comunicações e Participação S.a. Prefeito de Pelotas decreta situação de emergência devido à cheia no RS. 2015. Disponível em: <http://g1.globo.com/rs/rio-grande-do-sul/noticia/2015/10/prefeito-de-pelotas-decretasituacao-de-emergencia-devido-cheia-no-rs.html>. Acesso em: 01 out. 2018

GARCIA, M S D \& FERREIRA, M de P. (2018) Saneamento Básico: Meio Ambiente E Dignidade Humana - Dignidade Revista, [S.I.], v. 2, n. 3, p. 12, july 2017. ISSN 2525-698X. Disponível em: <http://periodicos.puc- rio.br/index.php/dignidaderevista/article/view/393>. Acesso em: 02 set. 2018

GUEDES, I B. Pesquisa De Leptospira Spp. Em Fêmeas Bovinas Pertencentes Ao Município De Novo Repartimento - Pará. São Paulo, 2017. Dissertação apresentada ao programa de Pós Graduação em Epidemiologia Experimental Aplicada às Zoonoses da Faculdade de Medicina Veterinária Zootecnia da Universidade de São Paulo.

HANSMANN, H.Z. Descrição e caracterização das principais enchentes e alagamentos de Pelotas-rs. 2013. 63f. Trabalho de Conclusão de Curso (TCC). Graduação em Engenharia Ambiental e Sanitária. Universidade Federal de Pelotas, Pelotas.

IBGE - Instituto Brasileiro de Geografia e Estatística - Cidades. Rio de Grande do Sul, 2017. Site oficial: <https://cidades.ibge.gov.br/>. Acesso em: 21 ago. 2018

MOURÃO, A. C. Variabilidade Espacial Da Salinidade Em Solo Cultivado Com Videira Irrigada No Vale Do São Francisco Em Petrolina-Pe. 2014, 52f.: il. Dissertação (Mestrado em Irrigação e Drenagem). Universidade Federal Rural do Semi-Árido, Mossoró, 2014.

NOMURA, A A U, CANGUSSÚ, J C, FRANCISCO, M I S, \& SOUZA, Z H de (2017) Saneamento Básico E Saúde Pública - In: I Colóquio Estadual de Pesquisa Multidisciplinar - 06, 07 e 08 de junho de 2017- Mineiros-GO.

HOLOS, ANO 35, v.3, e7940, 2019 
NUNES, H. M., SOARES,M do C. P., SARMENTO, V. P., MALHEIROS,A. P., BORGES, A. M., SILVA,I.S. da, \& PAIXÃO, J. F. da (2016) Soroprevalência Da Infecção Pelos Vírus Das Hepatites A, B, C, D E E Em Município Da Região Oeste Do Estado Do Pará, Brasil - Revista Pan-Amaz Saúde 2016; 7(1):5562.

OLIVEIRA, J. P. M., OLIVEIRA, J.M.O., BARRETO, E.S., SILVA, S. S. da, \& SILVA, S.S. da; MARACAJÁ, P B (2015) Saúde/Doença: As Consequências Da Falta De Saneamento Básico - INTESA - Informativo Técnico Do Semiárido (Pombal-PB), v.9, n 2, p 23-29, Jun -Dez, 2015.

PINHEIRO, R. S., ARAÚJO, L. A. de, CAETANO, K.A.A, MATOS, M.A. de, CARNEIRO, M.A.S., \& TELES, S.A. (2015) Endemicidade Intermediária Da Infecção Pelo Vírus Da Hepatite A Em Projetos De Assentamentos Rurais Do Sudoeste De Goiás, Brasil ArqGastroenterol - v. 52 no. 3 - jul-set. 2015

SANTOS, C de J., BRANDÃO, M.S., PEIXOTO, N.C.B, \& SILVA, S.N. (2018) Pibid Em Uma Escola Do Campo: Uma Proposta De Educação Ambiental Para Trabalhar Problemas Referentes Às Doenças De Veiculação Hídrica - Revista Brasileira de Educação Ambiental - Revbea, São Paulo, V. 13, No 1: 227-239, 2018.

SIQUEIRA, M. S., SANTOS, R., BORDIN, R. R., \& NUGEM, R. de C. (2017) Internações Por Doenças Relacionadas Ao Saneamento Ambiental Inadequado Na Rede Pública De Saúde Da Região Metropolitana De Porto Alegre, Rio Grande Do Sul, 2010-2014. Epidemiol. Serv. Saúde 26 (4) Oct-Dec 2017. <https://doi.org/10.5123/S1679-497420170004000>

SNIS. Sistema Nacional de Informações sobre Saneamento. Diagnóstico dos Serviços de Água e Esgoto - 2016. Brasília: SNSA/MCIDADES.

SOARES, J.A.S, ALENCAR, L.D. de, CAVALCANTE, L.P.S, \& ALENCAR, L.D. (2014) Impactos Da Urbanização Desordenada Na Saúde Pública: Leptospirose E Infraestrutura Urbana - LABORE Laboratório de Estudos Contemporâneos POLÊMICA Revista Eletrônica - v. 13, n.1, janeirofevereiro de 2014 p. 1006 - 1020.

WILDING, L.P., \& DREES, L.R. (1983) Spatial variability and pedology. In: WILDING, L.P.; SMECK, N.E.; HALL, G.F. (Eds.). Pedogenesis and Soil Taxonomy: Concepts and Interactions. New York: Elsevier, 1983. p.83-116. 